\title{
Epidemiology and Clinical Profile of Takotsubo Cardiomyopathy
}

\author{
Scott W. Sharkey, MD; Barry J. Maron, MD
}

\begin{abstract}
First described in Japan over 2 decades ago, takotsubo cardiomyopathy (TTC) has emerged as a unique cardiomyopathy with world-wide recognition, mimicking acute coronary syndrome. In early TTC experience, typical patients were older women, with a triggering emotional event, ST-segment elevation, and apical ballooning left ventricular (LV) contraction pattern. However, TTC is now more heterogeneous, occurring in males and younger individuals, without ST-segment elevation, as a spontaneous event in the absence of a trigger, and with diverse LV contraction patterns. Furthermore, TTC is more common than initially thought, now constituting $10 \%$ of women with suspected acute coronary syndrome. TTC is also associated with a broader range of psychological or physical triggers, including presentation during outpatient medical evaluations or hospitalization for acute illness. Although TTC has been considered a benign condition, it now carries a small but important risk for adverse outcomes, including cardiac arrest in $5 \%$. Hemodynamic instability requiring intervention with vasopressor drugs or intra-aortic balloon pump is necessary in $15 \%$ and in-hospital mortality is approximately $5 \%$, largely because of refractory cardiogenic shock or irreversible major comorbid conditions. Although complete cardiac recovery usually occurs rapidly, post-hospital survival may be less than the general population of similar age, largely because of concomitant illnesses. TTC may reoccur in up to $10 \%$ of patients, but $\beta$-blocking drugs are not absolutely preventive for initial or subsequent events. (Circ J 2014; 78: 2119-2128)
\end{abstract}

Key Words: Myocardial stunning; Takotsubo cardiomyopathy

$\mathbf{O}$ ver 25 years, takotsubo cardiomyopathy (TTC) has emerged as a novel and important form of acute cardiac failure characterized by distinctive and reversible left ventricular (LV) contraction abnormalities not mediated by epicardial coronary artery obstruction. TTC was first reported by Dote et al in 1991 in the Japanese language, ${ }^{1}$ but was largely unknown or considered obscure until the first reports from Europe and the United States appeared in the late $1990 \mathrm{s.} .^{2,3}$ From 2001 to 2010, TTC achieved increasing clinical visibility, with reports from Japan, United States, and Europe. ${ }^{4-12}$

In 2006, the American Heart Association formally recognized TTC as an acquired cardiomyopathy ${ }^{13}$ and the number of citations related to TTC has increased dramatically during the past decade from 8 (in 2003) to 246 (in 2013) and now to nearly 2,000 publications. ${ }^{14,15}$ Throughout this time, TTC acquired a variety of names (eg, apical ballooning syndrome, ampulla cardiomyopathy, stress-related cardiomyopathy, broken heart syndrome) most of which describe the unusual endsystolic LV shape and its association with triggering stressful events. ${ }^{14}$ The term "takotsubo cardiomyopathy" is now generally accepted in recognition of the initial name that Japanese investigators chose to describe the condition. ${ }^{16}$

\begin{abstract}
Epidemiology
Demographic Profile

A common feature of TTC is its propensity to affect older women, often in the postmenopausal years. ${ }^{7,17,18}$ In the US and Europe, a number of contemporary TTC studies report $90 \%$ to be women, aged 65-70 years of age. ${ }^{19-21}$ A recent report from a coronary care unit network in Tokyo noted a somewhat older average age of 74 years, which may reflect patient selection and in part the older age of the Japanese population. ${ }^{22}$ However, as experience with TTC has expanded, the number of cases reported in younger individuals at virtually any age has increased, including a 2 -year-old girl with a malignancy, ${ }^{23}$ and also in premenopausal women during pregnancy or childbirth. ${ }^{24}$ Notably, TTC in males, once thought to be exceedingly rare, now appears to constitute approximately $10 \%$ or more of cases, most commonly as a consequence of a physical stress trigger. ${ }^{25}$
\end{abstract}

\section{Incidence}

Approximately $2 \%$ of all patients ( $10 \%$ specifically in women) presenting to the hospital with suspected acute coronary syndrome (ACS) are ultimately identified with TTC. ${ }^{16,26}$ An estimate based on the 2008 Nationwide Inpatient Sample (repre-

Received July 15, 2014; accepted July 16, 2014; released online August 5, 2014

Minneapolis Heart Institute Foundation at Abbott Northwestern Hospital, Minneapolis, MN (S.W.S., B.J.M.); the Hypertrophic Cardiomyopathy Center, Minneapolis, MN (B.J.M.), USA

Mailing address: Scott W. Sharkey, MD, Minneapolis Heart Institute Foundation, Suite 300, 920 East $28^{\text {th }}$ Street, MN, USA. E-mail: scott.sharkey@allina.com

ISSN-1346-9843 doi:10.1253/circj.CJ-14-0770

All rights are reserved to the Japanese Circulation Society. For permissions, please e-mail: cj@j-circ.or.jp 

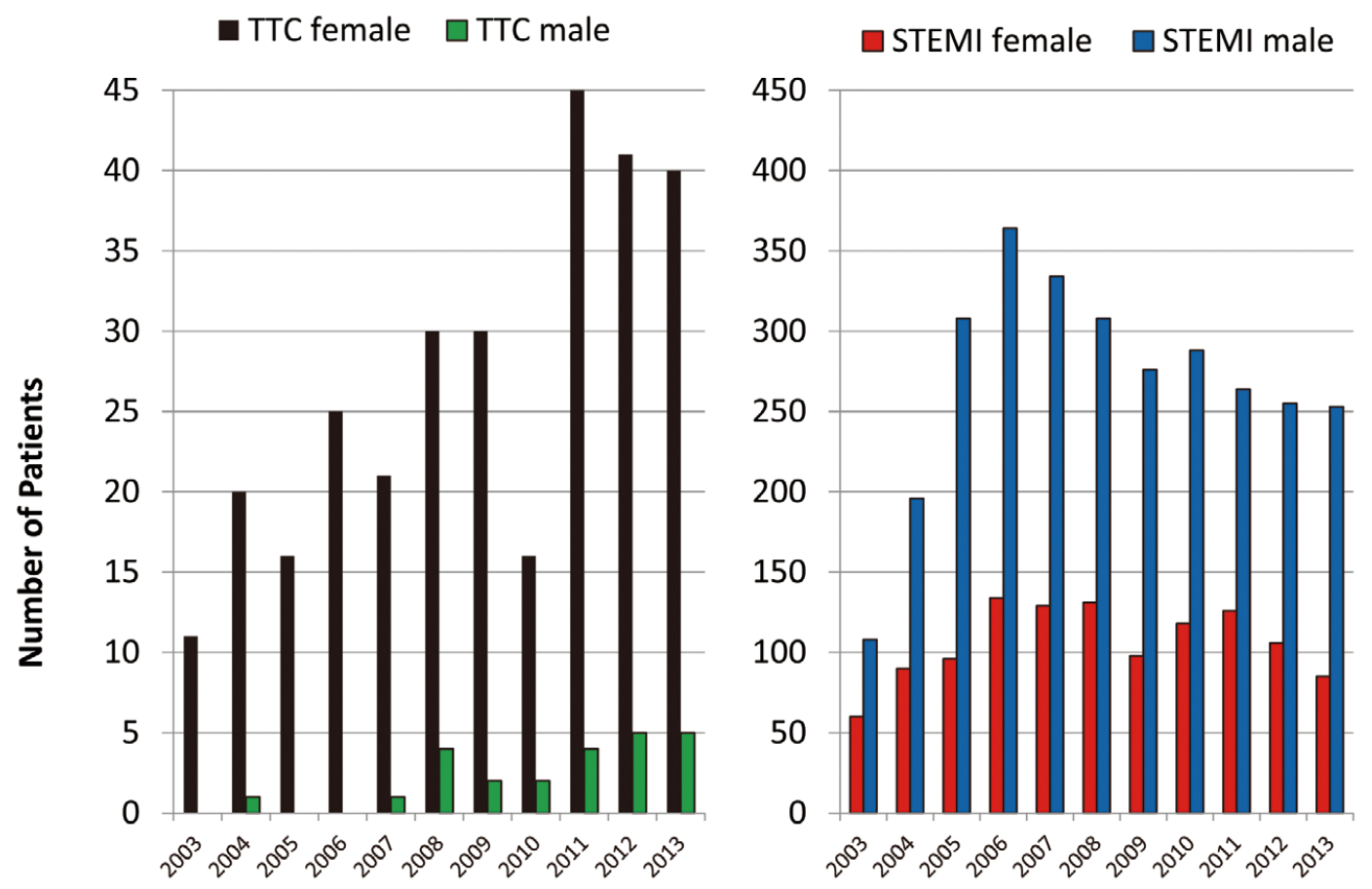

Figure 1. Number of patients with takotsubo cardiomyopathy (TTC) compared with ST-segment elevation myocardial infarction (STEMI). Tabulated by year from 2003 to 2013 at Minneapolis Heart Institute. TTC patients: females ( $n=295)$, males ( $n=24)$; STEMI patients: females $(n=1,173)$, males $(n=2,954)$.

senting $20 \%$ of USA community hospitals) yielded 6,837 patients with a TTC discharge diagnosis. ${ }^{27}$ In our Minneapolis Heart Institute experience, the number of cases has progressively increased since 2001 now up to 50 cases annually, compared with approximately 120/year for women with ST-segment elevation acute myocardial infarction (MI), a ratio of 2.4:1 (Figure 1).

\section{Global Occurrence}

Although the initial TTC reports were in Japanese patients, this cardiomyopathy is now recognized to have widespread geographical distribution, with reports from 6 continents and more than 50 countries, although with little difference in its clinical expression. To date, TTC has been reported in a variety of races, but uncommonly in Hispanics and AfricanAmericans. ${ }^{28}$ Although large-scale direct comparisons have not been made between racial groups, 1 small study found no major distinctions in clinical characteristics among Asian and Caucasian TTC patients. ${ }^{29}$

\section{Temporal Variability}

Available data suggest a modest temporal pattern of occurrence for TTC. For example, Sharkey et $\mathrm{al}^{30}$ and Manfredini et $\mathrm{al}^{31}$ reported a circadian influence with morning peak and evening nadir, which may be related to a morning surge in stress-related hormones or disproportionate exposure to stressful events (eg, medical procedures) at certain times of the day. Substantial variability has been reported for seasonal or daily TTC onset, although 2 reports have suggested a summer peak. ${ }^{32,33}$ Clustering of TTC events has also been reported in association with natural disasters such as earthquakes and floods..$^{34,35}$

\section{Clinical Profiles}

\section{Presentation}

TTC patients generally present in 2 distinct clinical scenarios: with abrupt onset at home or in the community, or alternatively in a healthcare-related setting during evaluation or treatment of an illness.

Patients with prehospital TTC onset typically present to an emergency department with acute chest pain or dyspnea, symptoms that are often indistinguishable from ACS. ${ }^{16,25,36}$ Consequently, these patients are usually admitted to a specialized cardiac unit and are often initially treated with aspirin and anticoagulants.

In contrast, TTC onset in healthcare settings occurs in circumstances such as during surgical procedures (eg, orthopedic, abdominal, neurologic, cosmetic, cardiac), with acute medical conditions (eg, sepsis, stroke, malignancy, acute respiratory failure, trauma), or during outpatient procedures (eg, endoscopy, tissue biopsy, chemotherapy, stress testing). In these situations, TTC may manifest as arrhythmia, hypotension, acute pulmonary edema, abnormal ECG, or troponin elevation. ${ }^{37,38}$

\section{Triggers}

A hallmark of TTC is its frequent association with a triggering stressful event. In early reports, most of these events involved emotional trauma. ${ }^{11,12}$ As experience with TTC expanded, a substantial association with physical stressors has emerged. ${ }^{7,16,25}$ Some specific examples are: laryngeal obstruction from tumor; gastric ulcer with profound hemorrhage; subarachnoid hemorrhage; diverticulitis with septic shock; and diabetic gastroparesis. However, notably, TTC may also occur 
Table. Diversity of Stressors Triggering Takotsubo Cardiomyopathy Events

\section{Emotional triggers}

Anger/frustration

- Heated argument with landlord over rent

- Argument with husband (afflicted by dementia)

- Anger and frustration related to organizing a community event

\section{Financial or employment problems}

- Gambling loss including passing bad checks

- Personal business failure with loss of life savings

- Discovery of large business debt

- Stress during meeting with work manager

- Stressful beginning to a new job

- Job loss resulting in need to live in a homeless shelter

\section{Grief/loss}

- Tenth anniversary of son's death

- Found husband unresponsive in driveway after shoveling snow (patient performed CPR)

- Husband with post-op cardiac arrest and anoxic encephalopathy

- Withdrawal of life support for brother

- Advised of son's death in military

- Sense of loss after retiring from life-long occupation

- Impending death of husband from cancer

- Expressing grief at memorial service for public figure (US Senator)

- Euthanasia of family dog

- Reflecting on death of son-in-law during church meeting

\section{Interpersonal conflict}

- Lengthy divorce culminating in sale of home of 28 years

- Separation from husband

- Severe depression with suicidal ideation

- Failure to keep up with daughter during bicycle race

- Altercation with mentally ill daughter

- Discussing brother's methamphetamine addiction and alcoholism

- Relocation of permanent residence

- Physical domestic abuse by spouse

- Estrangement from daughter

. Overwhelming emotion during $50^{\text {th }}$ wedding anniversary

- Informed that best friend moving great distance

- Upsetting phone call from friend

- Sexual abuse by relative

- Disclosure that unmarried daughter is pregnant

- Loss of child custody

(Table continued the next column.)

\section{Panic/fear/anxiety}

- Flat tire while driving a remote road without cell phone

Accidental fall outdoors during Minnesota winter with hip fracture (feared freezing to death)

- Legal deposition regarding motor vehicle accident

- Lost while driving in unsafe neighborhood at night

- Frightened by alarm signal from carbon monoxide monitor

Lost with flat tire while driving mother to physician appointment

Poultry barn burned down (fearing loss of chickens)

Anxiety regarding a public speaking event

- Sudden illness of husband

- Basement flood during intense thunderstorm

- Anxiety about elevated blood pressure

Anxiety about elective cardioversion for atrial fibrillation

Panic while trying to load store purchases into car during bitter cold

- Fall at home while alone with fear of not being found

- Fall at home with hip fracture; unable to call for help

- Panic attack during lung biopsy for suspected malignancy

. Caught in storm on pontoon boat

Identity theft

. Flooding of home from frozen and burst water pipes

Physical triggers

\section{Acute respiratory failure}

- Chronic obstructive pulmonary disease exacerbation (some with bronchodilator use)

- Pulmonary embolism

- Laryngeal obstruction from neoplasm

- Respiratory distress from influenza

- Acute epiglottitis (Pasteurella multocida) requiring intubation

Central nervous system conditions

- Subarachnoid hemorrhage

Brain contusion from accidental fall

- Ruptured cerebral aneurysm

- Vasculitis

Migraine headache treated with zolmitriptan

- Seizure

Brain abscess

- Vertebral artery dissection with stroke

Malignancy

- Chemotherapy for esophageal cancer

- Metastatic carcinoid tumor

- Adenocarcinoma of lung metastatic to brain

- Chemotherapy for metastatic colon cancer

- Advanced cervical sarcoma

(Table continued the next page.)

diac illness.

The diversity of stressors associated with TTC is striking and ranges from the profound to the mundane (Table). ${ }^{7,16,25,39}$ In some reports, TTC has been linked to conditions that produce high levels of circulating catecholamines, including pheochromocytoma and paraganglioma. ${ }^{40,41}$ Administration of catecholamine drugs (eg, epinephrine, dobutamine) in excessive, or even therapeutic, doses has also been associated with TTC onset. ${ }^{42}$ These observations support the hypothesis that elevated catecholamine levels may be involved in the pathophysiology of TTC. ${ }^{12}$ 


\begin{tabular}{l} 
Infection \\
- Urosepsis \\
- Spinal fusion wound infection \\
- Peritonitis from ischemic bowel \\
- Influenza B \\
Post-surgical/fracture \\
- Hysterectomy and bilateral oopherectomy \\
- Knee athroplasty \\
- Discectomy and T12-S1 fusion for scoliosis \\
- Cholecystectomy \\
- Decompression of spinal stenosis \\
- Pericardiocentesis \\
- Hip fracture \\
- Surgical debulking of ovarian cancer \\
- Pelvic hemorrhage after vaginal hysterectomy \\
Other \\
- Nosebleed treated with phenylephrine \\
- Accidental excessive home insulin dose \\
- Intentional phenergan overdose \\
- Dobutamine stress test \\
- Gastrointestinal bleeding with significant anemia \\
- Acute rejection of renal transplant \\
- Diabetic gastroparesis \\
- Allergic drug reaction \\
- Prolonged viral illness with dehydration \\
- Hypertensive crisis \\
- Withdrawal from alcohol \\
- Snow removal from roof in below zero (F) temperature \\
- Accidental fall out of a canoe into cold water for 30 min \\
- Nausea and vomiting after colonoscopy procedure \\
- Hiking in hot desert at high elevation \\
- Electroconvulsive treatment of depression \\
\hline
\end{tabular}

\section{Electrocardiography}

The 12-lead ECG on presentation is abnormal in most TTC patients, usually with ischemic ST-segment and T-wave changes. ${ }^{7,25}$ Most commonly, in 40-50\% of cases, ST-segment elevation is present in the precordial leads, resembling an acute anterior MI pattern because of occlusion of the left anterior descending (LAD) coronary artery (Figure 2). Some investigators have suggested that ST-segment shifts in leads aVR and $\mathrm{V} 1$ are useful for identification of TTC, ${ }^{43}$ but the 12-lead ECG pattern cannot distinguish the 2 conditions with certainty. ${ }^{44,45}$ Other common ECG patterns in TTC include: diffuse T-wave inversion, anterior Q waves, and left bundle branch block. The ECG may be normal in approximately $2 \%$ of patients. ${ }^{7,18}$

During hospitalization, the ECG in TTC typically evolves with progressive T-wave inversion and QT lengthening over several days (Figures 2,3), although these changes also may be present on admission in patients with delayed presentation. This ECG pattern is similar to that in reperfusion-treated acute MI with minimal biomarker release, considered a manifestation of electrophysiologic stunning. ${ }^{46}$ It has been suggested that the prolonged QT interval may predispose TTC patients to torsade de pointes ventricular tachycardia (Figure 3). ${ }^{47}$

\section{Cardiac Biomarkers}

In TTC, the initial troponin level is abnormal in $90 \%$ of patients, often leading to a misdiagnosis of ACS. Furthermore, the dynamic troponin release pattern is similar to that of acute
MI caused by obstructive coronary artery disease. ${ }^{48}$ However, in contrast to ACS, TTC events are characterized by lower peak levels of troponin, generally $<1 \mathrm{ng} / \mathrm{ml}$, and creatine kinase, generally no greater than 500 U/L.7,17,18,25 The small troponin and creatine kinase release in the presence of substantial but reversible LV systolic dysfunction, characteristic of TTC, is consistent with acute myocardial stunning.

$\mathrm{B}$-type natriuretic peptide (BNP) and N-terminal pro-BNP (NT-proBNP) levels may be significantly elevated (median $>600$ and $4,000 \mathrm{pg} / \mathrm{ml}$, respectively), often 3-4-fold greater than in patients with ACS, peaking at $48 \mathrm{~h}$ after presentation, and with persistent elevation for up to 3 months. ${ }^{49}$ Although the BNP and N-T-proBNP levels are comparable to those in patients with acutely decompensated heart failure (HF), 1 small series of TTC patients $(n=56)$ reported no association of these biomarkers with pulmonary congestion or pulmonary capillary wedge pressure. On the other hand, these biomarkers were associated with lower LV ejection fraction and higher plasma catecholamine levels and thereby with severity of disease. ${ }^{49}$

\section{Ventricular Contraction Patterns}

To date, 3 unique patterns of abnormal LV contraction have been identified, classified as apical, mid, and basal ballooning (Figure 4). ${ }^{7,16-18,25,50-52}$ In each, the LV wall motion abnormality is circumferential and distinct from that caused by obstructive coronary artery disease.

LV apical ballooning pattern was the first to be described as characteristic of TTC, and is present in approximately $75 \%$ of patients. ${ }^{1}$ The unique end-systolic apical ballooning configuration reminded Japanese physicians of the takotsubo, a submersible pot used to trap octopus, leading to the distinctive name based on the angiographic configuration. In the occasional patient, the TTC apical ballooning pattern is similar to the contraction abnormality caused by ischemia from significant LAD coronary artery stenosis, which extends beyond the LV apex to supply the inferior wall ("wrap-around" LAD). ${ }^{53}$

The mid-ventricular ballooning pattern (Figure 4), in which the mid-LV is akinetic, with normal apical and basal contraction, is present in approximately $25 \%$ of patients. ${ }^{7,51}$ The basal ballooning pattern (Figure 4) is rare and encountered in only $1 \% .^{41}$ There does not appear to be any particular clinical significance attached per se to these distinctive contraction patterns.

Segmental wall motion abnormalities involving the apical right ventricle are identifiable with echocardiographic or cardiac magnetic resonance (CMR) imaging in $25 \%$ of patients (Figure 4), and are observed with either LV apical or midventricular ballooning, although a few case reports suggest it can occur in isolation. ${ }^{7,54}$ In some reports, right ventricular dysfunction has been a marker for TTC severity and associated with hemodynamic instability and $\mathrm{HF}$, lower ejection fraction, and longer hospital stay. ${ }^{26}$

\section{Cardiac Stunning}

From its initial description, a dramatic and characteristic hallmark of TTC has been the complete reversibility of left (and right) ventricular contraction abnormalities and symptoms within days to weeks, although delayed recovery of 1-2 months has been reported in a few patients. ${ }^{7,16-18,25}$ Longer persistence of LV systolic dysfunction (beyond 2 months) should prompt consideration for a coexisting cardiomyopathy. In TTC, the almost universal absence of delayed gadolinium hyperenhancement on CMR in the region of abnormal LV contraction indicates tissue viability and may explain myocardial recovery in TTC. ${ }^{7,50,55}$

Abnormalities of myocardial perfusion, sympathetic nerve 


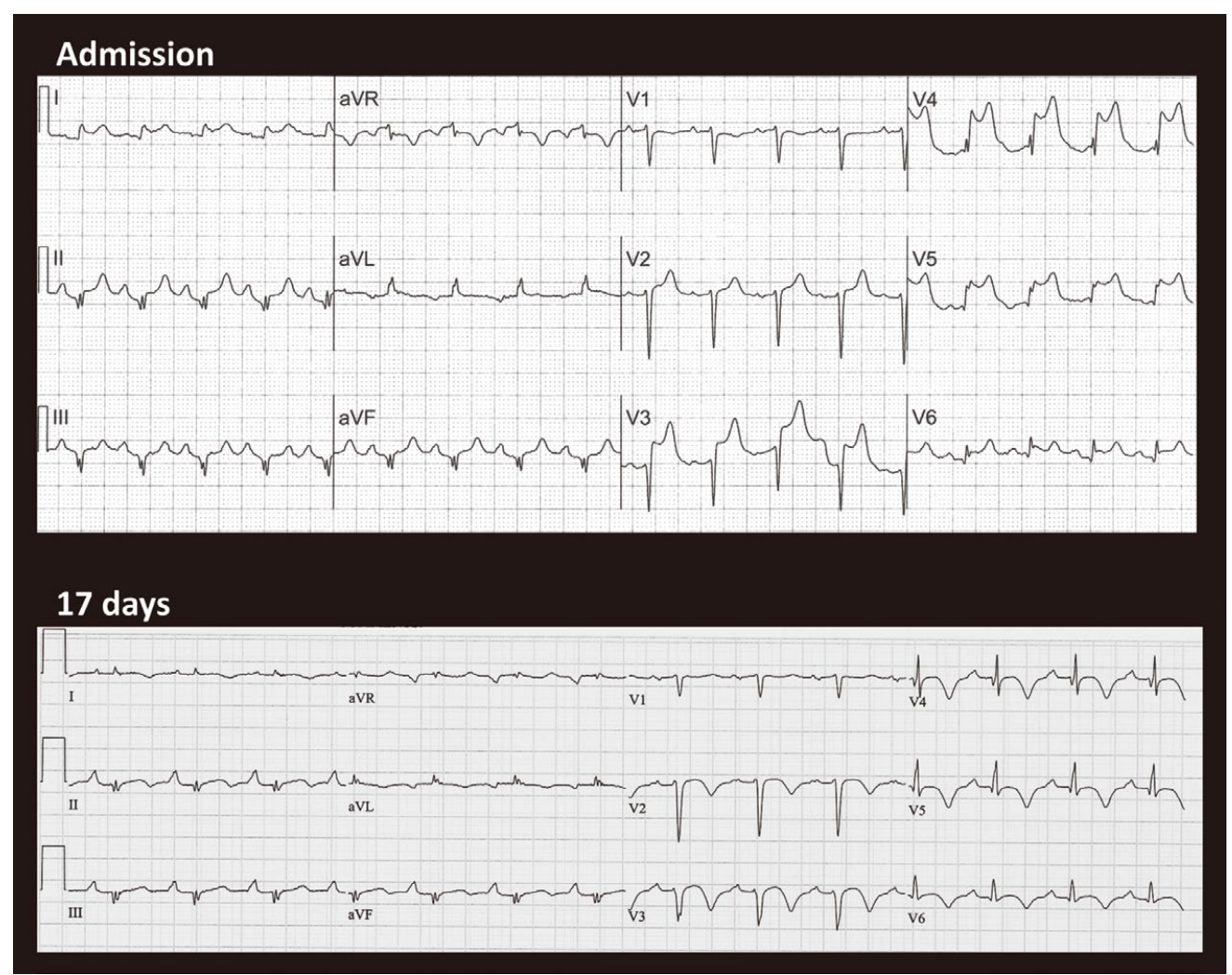

Figure 2. Evolution of ECG pattern in takotsubo cardiomyopathy (TTC). Serial 12-lead ECGs in a 56-year-old woman with apical ballooning triggered by gastric hemorrhage demonstrate initial ST-segment elevation with subsequent evolution of T-wave inversion and QTc prolongation. (Top) 12-lead ECG on presentation with ST-segment elevation in leads V2-6, I, II, and reciprocal ST-segment depression in lead aVR. (Bottom) ECG 17 days after admission demonstrates diffuse and deep T-wave inversion, and QT prolongation (QTC=531 $\mathrm{ms})$.

activity, and fatty acid metabolism, corresponding to the region of abnormal wall motion, have been demonstrated with a variety of techniques and are consistent with a reversible stunning process involving the coronary microcirculation, myocardial energy production, and cardiac sympathetic nervous system activity (Figure 5). ${ }^{56-59}$

\section{Cardiac Catheterization}

Noninvasive methods alone do not reliably distinguish TTC from ACS, and urgent coronary angiography is necessary to exclude significant obstructive coronary artery disease that would require revascularization. ${ }^{36}$ Most TTC patients have angiographically normal coronary arteries or only mild atherosclerosis, although some will have reduced contrast flow rate in the epicardial coronary arteries in the absence of coronary atherosclerosis, probably representing downstream microvascular stunning that usually resolves within several weeks. ${ }^{44,60}$ In uncertain situations, such as suspected coronary embolism or equivocal coronary angiographic findings, contrast-enhanced $\mathrm{CMR}$ is useful because late gadolinium enhancement is rarely evident in TTC, but frequently present in patients with ACS.61

Recently, "incidental" obstructive coronary artery disease ( $>75 \%$ stenosis in an epicardial vessel remote from the area of abnormal wall motion) has been reported in a minority of TTC patients (ie, 10\%) and this possibility should be considered before performing percutaneous coronary intervention. ${ }^{62}$

\section{Heart Failure in TTC}

TTC is a novel form of acute HF characterized by abrupt loss of regional LV contractile function involving a substantial myocardial mass. Ejection fraction is acutely reduced to 30$35 \%$, and below that observed during acute anterior MI, likely because of a larger mass of akinetic myocardium (Figure 6).,63 LV stroke work is $50 \%$ of normal, with markedly increased end-systolic volume reflecting major impairment of LV pump function and leading to reduction in stroke volume and cardiac output. ${ }^{63}$ Furthermore, LV diastolic function is also acutely disturbed, with an upward shift in the LV diastolic pressurevolume curve, resulting in substantially elevated LV end-diastolic pressure without significant increase in LV end-diastolic volume. ${ }^{63}$ Under these circumstances, TTC patients may experience clinically important hemodynamic instability, including profound hypotension (requiring intervention with inotropic drug therapy and/or intra-aortic balloon pump [IABP]), pulmonary edema, and cardiogenic shock. ${ }^{16,25}$ A recent Italian report of 227 patients noted acute HF (pulmonary edema and/ or oxygen desaturation requiring intervention) in $20 \%$ and cardiogenic shock in $8 \%,{ }^{21}$ and a TTC registry from Germany and Austria (324 patients) reported pulmonary edema in $8 \%$ and cardiogenic shock in $4 \% .{ }^{20}$ In our 337 TTC patients at the Minneapolis Heart Institute, $15 \%$ had unstable hypotension requiring inotropic drugs or IABP, two-thirds of whom had acute pulmonary edema or cardiogenic shock. Taken together, 


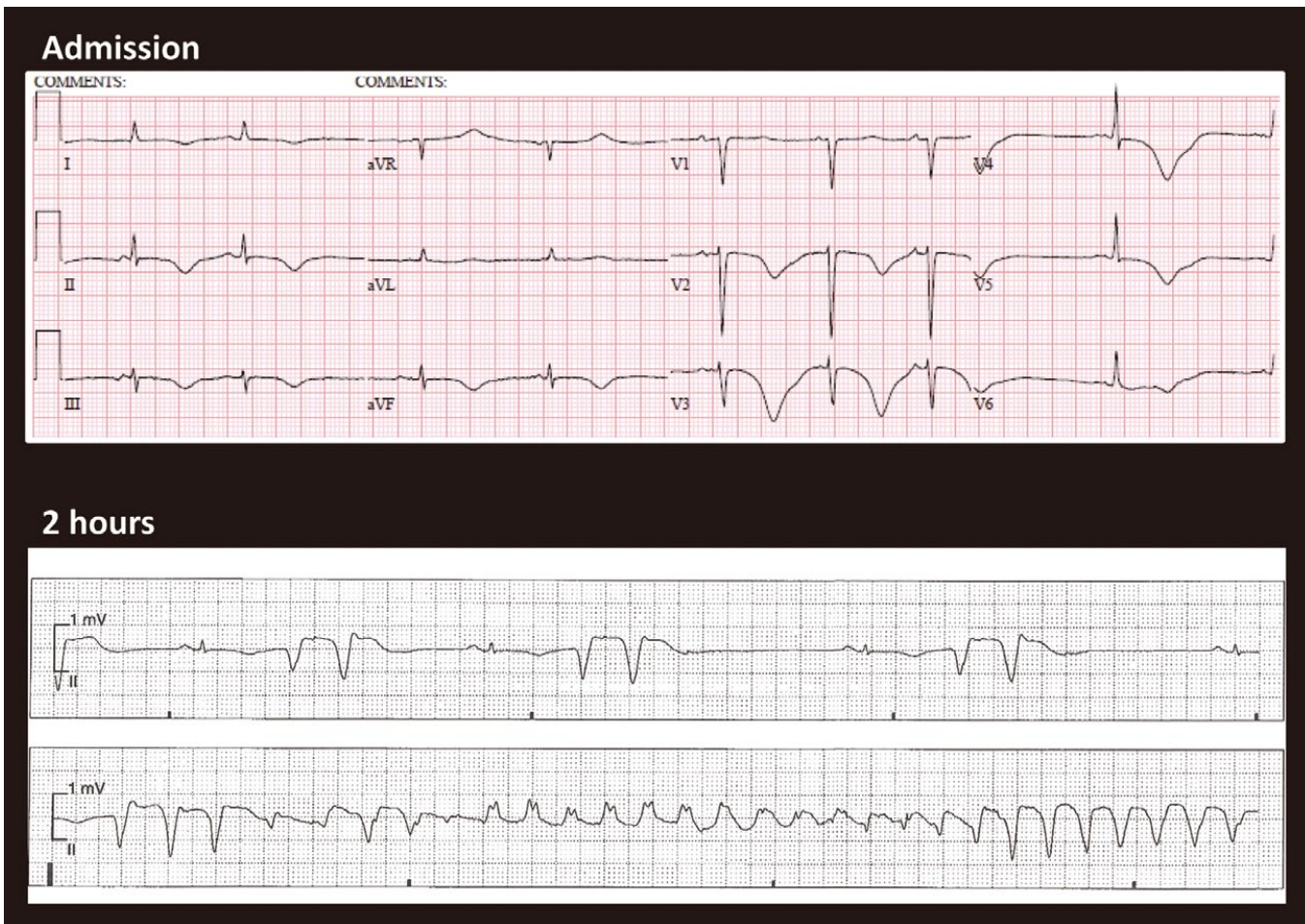

Figure 3. Occurrence of torsade de pointes (TdP) ventricular tachycardia in an 84-year-old woman with an apical ballooning takotsubo cardiomyopathy (TTC) event triggered by emotional stress. (Top) Admission ECG demonstrates sinus bradycardia, prominent T-wave inversion, and QTc prolongation to $549 \mathrm{~ms}$. (Bottom) Continuous 18-s recording of lead II rhythm strip $2 \mathrm{~h}$ after admission shows sinus bradycardia with paired premature ventricular contractions followed by TdP ventricular tachycardia, which self-terminated. The patient received a permanent pacemaker for underlying sinus node dysfunction and TdP resolved with higher heart rate.

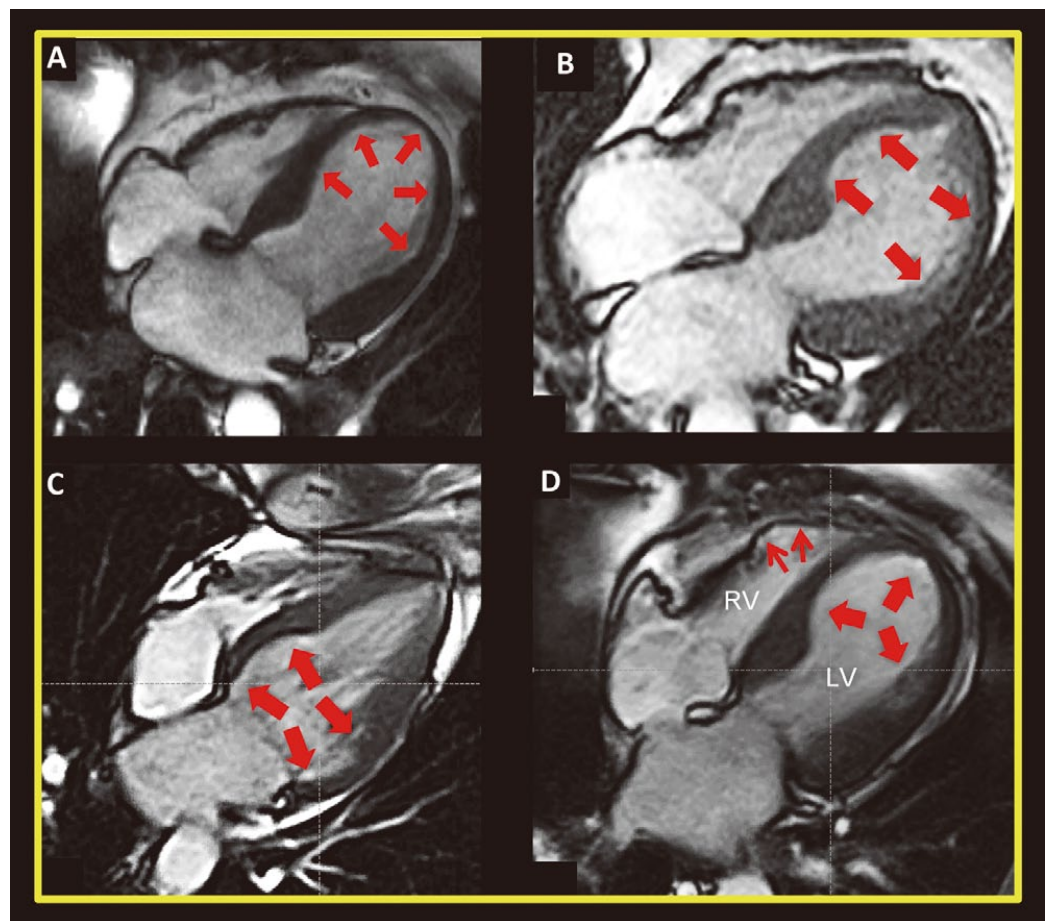

Figure 4. Diversity of left and right ventricular contraction patterns in takotsubo cardiomyopathy (TTC) demonstrated by cardiac magnetic resonance imaging in the horizontal long-axis view at end-systole. (A) Apical ballooning with akinesia in mid- and apical left ventricular (LV) segments (arrows); (B) mid-ventricular ballooning with akinesia in only the midLV segments (arrows); (C) basal ballooning with akinesia in basal LV segments (arrows); (D) RV apical dyskinesia (thin arrows) associated with LV apical ballooning (arrows). Adapted with permission from Sharkey SW. . $^{2}$ 


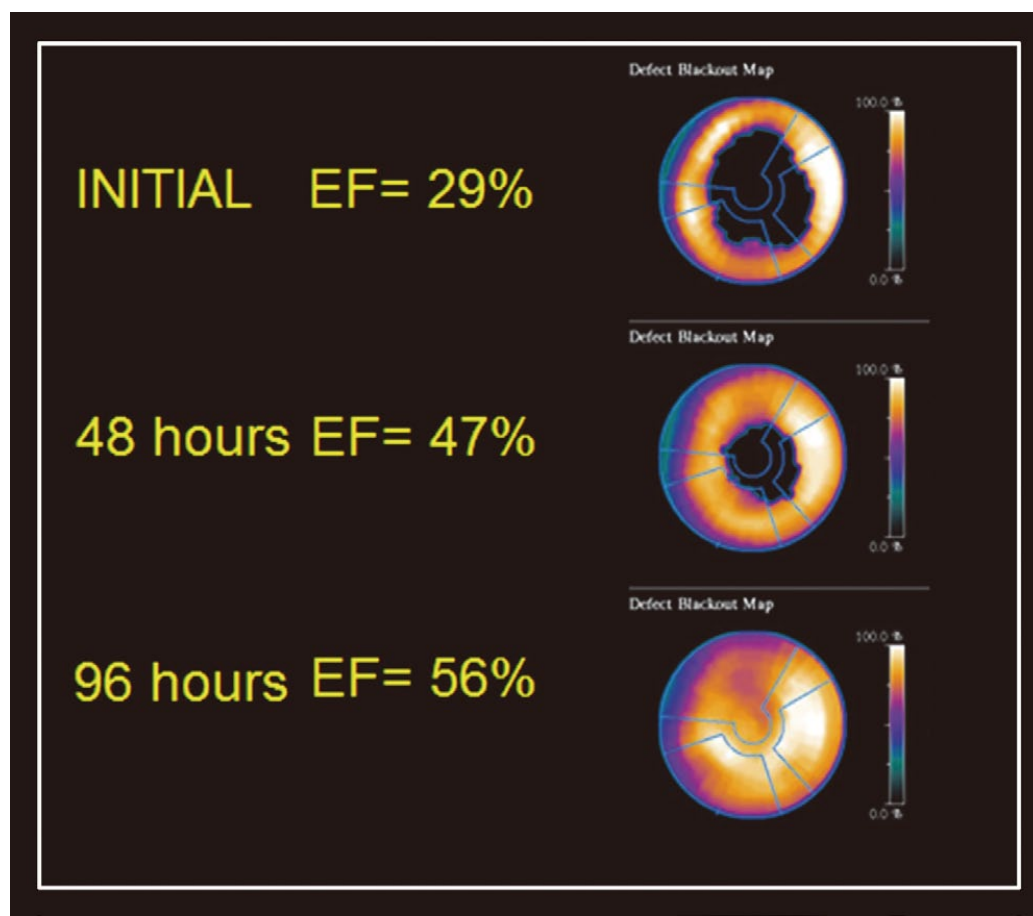

Figure 5. Myocardial contractile and perfusion stunning in takotsubo cardiomyopathy (TTC) in a 55-year-old woman with emotional stress-induced apical ballooning. Serial single-photon emission computed tomography (SPECT) images at rest show left ventricular (LV) ejection fraction (EF) and LV perfusion map in a polar plot display (normal perfusion is depicted in bright orange-white and abnormal perfusion in black). (Top) Initial study: EF is $29 \%$ with circumferential LV perfusion defect not corresponding to a single coronary artery distribution. (Middle) At 48h: EF improved to $47 \%$ and the LV perfusion defect is substantially smaller. (Bottom) At 96h: LVEF and perfusion have both normalized. Adapted with permission from Sharkey SW. ${ }^{52}$
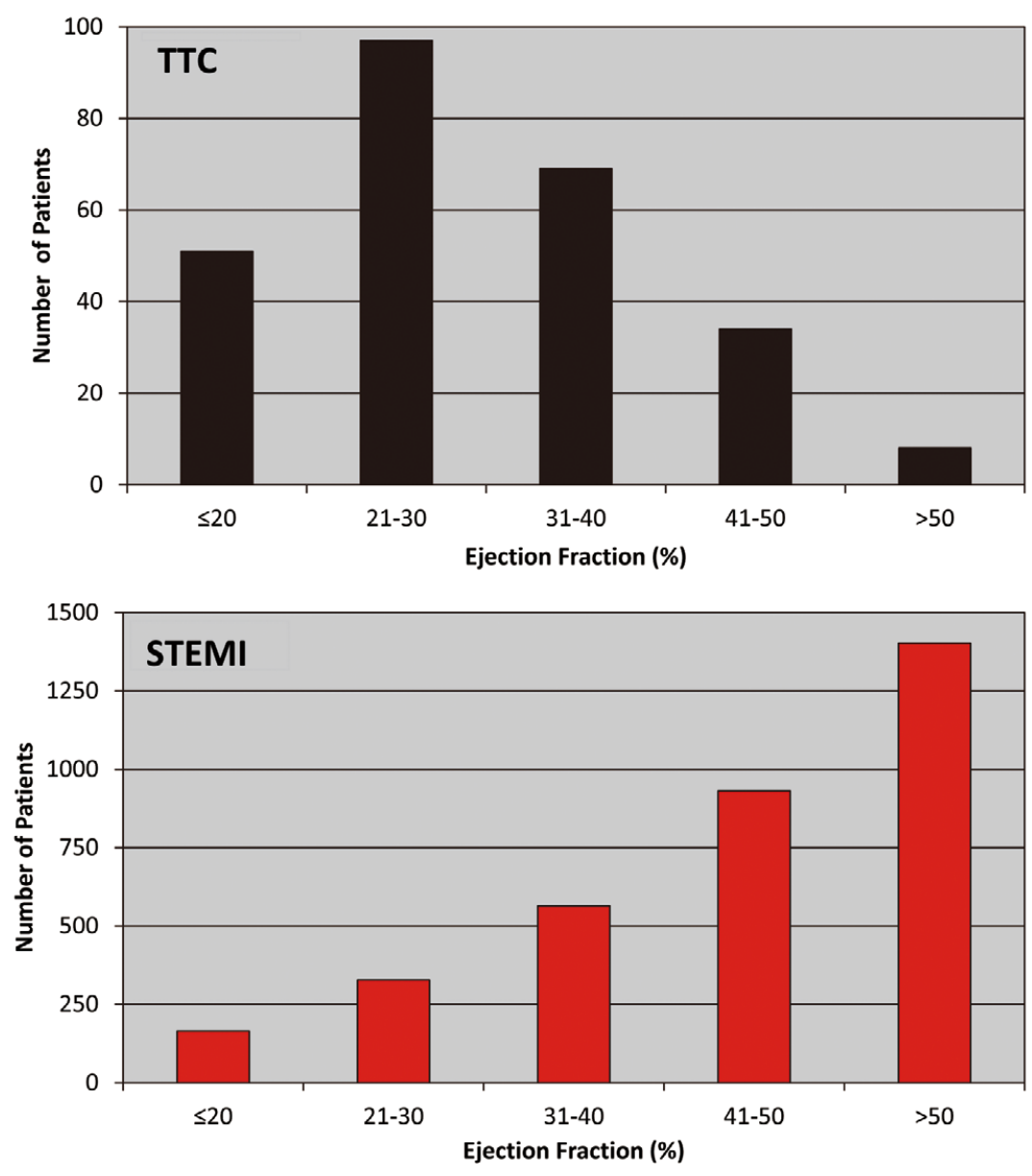

Figure 6. Distribution of ejection fraction (EF) on admission for takotsubo cardiomyopathy (TTC) compared with ST-segment elevation myocardial infarction (STEMI). (Top) TTC in 330 consecutive patients. (Bottom) STEMI in 3,954 consecutive patients. As a group, the EF in TTC is significantly lower than in STEMI: $32 \pm 11 \%$ vs. $47 \pm 14 \%$, respectively, $\mathrm{P}<0.001$. 


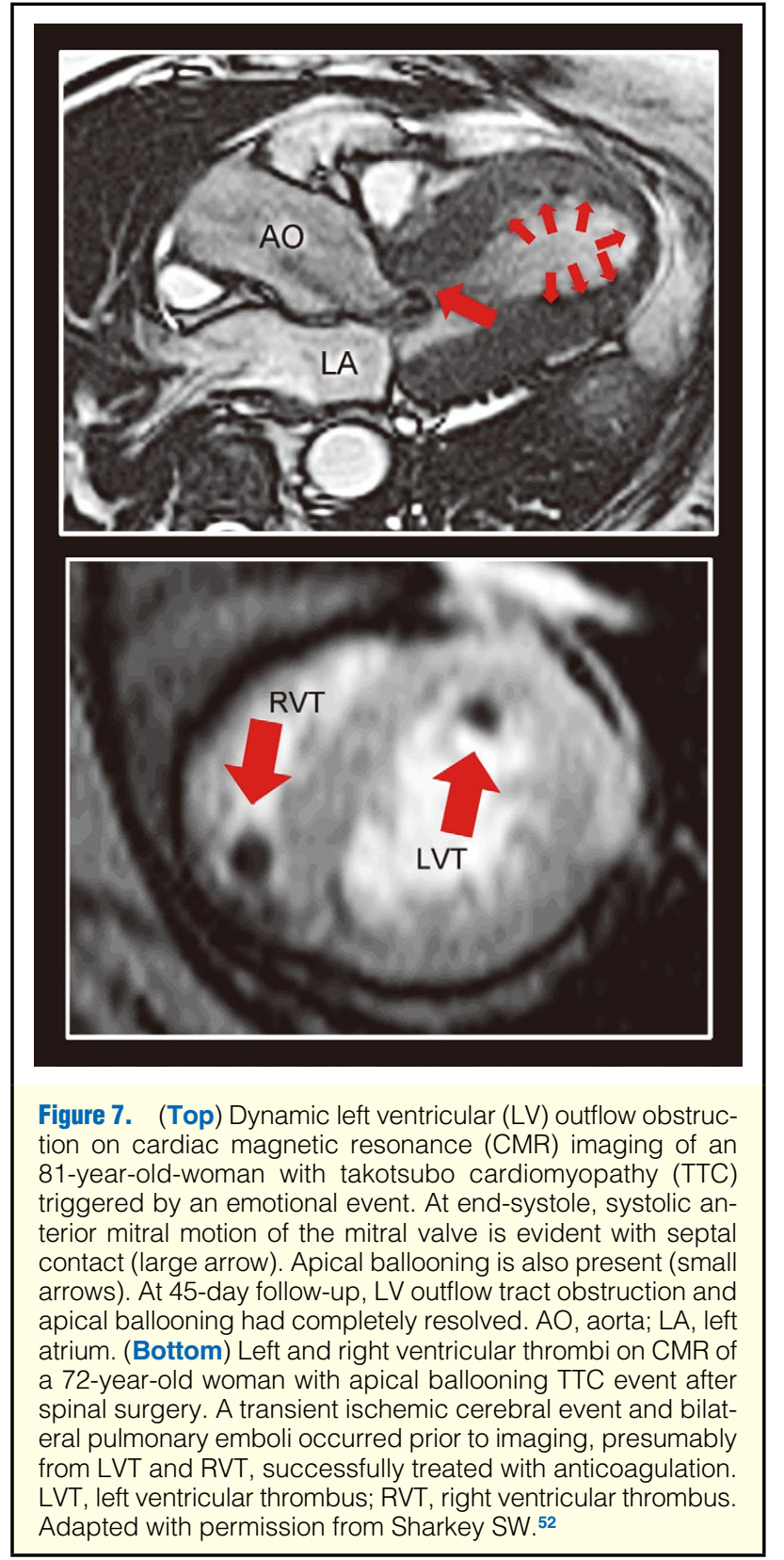

these observations suggest severe hemodynamic instability occurs in $10-20 \%$ of TTC patients.

Hypotension usually responds to intravenous vasopressor drugs, including dopamine, dobutamine, phenylephrine, norepinephrine, and vasopressin. However, the therapeutic use of catecholamine drugs in TTC is a concern because these agents have been implicated in the pathophysiology of this condition, leading some investigators to advocate the use of non-catecholamine vasopressor drugs to treat hypotension in TTC patients. ${ }^{25}$ More profound hemodynamic compromise may require temporary support with IABP or LV assist device. In rare circumstances, IABP might cause or worsen LV outflow tract obstruction by reducing intracavitary volume. ${ }^{64}$

In addition to reduced LV ejection fraction, several additional factors potentially contribute to hemodynamic instability, including local myocardial edema (present in up to $80 \%$ on magnetic resonance imaging) leading to impaired LV com- pliance, ${ }^{50}$ or dynamic LV outflow tract obstruction and mitral regurgitation secondary to systolic anterior motion of the mitral valve (in 10-20\% of patients) (Figure 7). ${ }^{65}$ Subaortic obstruction is more common with the apical ballooning pattern, may be provoked or exacerbated by catecholamine drugs used to treat hypotension, and is associated with mitral regurgitation. Persistence of mitral valve systolic anterior motion and outflow tract obstruction (with septal hypertrophy) after recovery may indicate coexisting hypertrophic cardiomyopathy. Isolated acute reversible mitral valve regurgitation has been reported in $20 \%$ of TTC patients and is associated with acute pulmonary edema and cardiogenic shock. ${ }^{21}$

\section{Outcome}

Although initially regarded as an almost uniformly benign and reversible condition, it is now evident that TTC carries with it a not inconsequential risk for adverse outcome.

Arrhythmias Life-threatening arrhythmias are part of the clinical spectrum of TTC (in $\approx 2 \%$ of patients), including ventricular fibrillation, torsade de pointes ventricular tachycardia, pulseless electrical activity, and asystole on presentation or during hospitalization. ${ }^{47,66}$ In patients experiencing cardiac arrest, it may be uncertain whether TTC should be incriminated as the cause or alternatively the consequence of the arrhythmia. The profound stress of cardiac arrest and subsequent resuscitation (sometimes with administration of epinephrine) can itself trigger a TTC event. Furthermore, a catastrophic non-TTC medical event (eg, acute respiratory failure or intracranial hemorrhage) could potentially cause cardiac arrest associated with TTC.

Torsade de pointes occurs in a subset of TTC patients in the setting of QT prolongation, typically $>500 \mathrm{~ms}$ (Figure 3). ${ }^{67}$ Male patients and those patients with bradycardia, heart block, and atrial fibrillation appear to be more susceptible. ${ }^{68}$ Because lengthening of the QT interval may occur after onset of the event, it is prudent to continue rhythm monitoring at least until hospital discharge; drugs that promote QT prolongation should be used judiciously or avoided.

In our Minneapolis Heart Institute TTC cohort, occurrence of cardiac arrest was $4 \%$, which exceeds that reported in the literature and may reflect increased awareness of TTC or the establishment of a local therapeutic hypothermia program resulting in increased referrals to our hospital. In one-half of these patients, a major noncardiac event (acute respiratory failure from chronic obstructive lung disease, subarachnoid hemorrhage) immediately preceded the cardiac arrest. However, in the other patients the TTC event itself was the only identifiable substrate for cardiac arrest, and each of these patients received a secondary prevention implantable defibrillator. Taken together, these observations raise the possibility that TTC may be a cause of unexplained sudden death in older patients.

Embolic Events Akinetic segments within the left and right ventricles provide the substrate for endocardial thrombus formation. Ventricular thrombi may be present in approximately $5 \%$ of TTC patients, may be multiple, and located at sites distinctly different from those in acute MI and can lead to systemic and pulmonary embolic events (Figure 7). ${ }^{7,17,18,25} \mathrm{CMR}$ has proven to be more sensitive than 2-dimensional echocardiography for detection of ventricular thrombi in TTC, ${ }^{50,69}$ and anticoagulation should be considered until the risk of thrombus has resolved associated with normalized myocardial contraction.

In-Hospital Mortality Hospital mortality in TTC is low despite the severity of acute HF and LV systolic dysfunction, and $>95 \%$ of patients experience complete cardiac recovery. 
In the Minneapolis experience, $97 \%$ of TTC patients survived to hospital discharge (including several who experienced pulmonary edema or cardiogenic shock as complications), with ejection fraction increasing from $32 \%$ on admission to $57 \%$ at follow-up. All in-hospital TTC deaths came from a high-risk subgroup comprising patients with cardiac arrest or marked arterial hypotension requiring intravenous vasopressors and/ or IABP. Notably, each nonsurvivor also had an irreversible noncardiac condition (eg, subarachnoid hemorrhage, acute respiratory failure, malignancy) with the potential to compromise clinical status and adversely influence short-term survival. Other investigators have also noted the importance of such coexisting noncardiac conditions affecting hospital survival. ${ }^{70}$ Large TTC patient registries have reported in-hospital mortality of $2 \%$ in Germany and Austria $(n=324)$, and $3 \%$ in Italy $(\mathrm{n}=227),{ }^{20,21}$ and $4 \%$ in the US National Inpatient Sample $(\mathrm{n}=24,701),{ }^{71}$ as well as an 11 -country survey $(\mathrm{n}=2,120) \cdot{ }^{72} \mathrm{LV}$ free wall rupture and ventricular septal defect are known complications leading to TTC-related death. ${ }^{73-76}$

Post-Hospital Survival Assessments regarding long-term post-TTC survival are limited and unavoidably influenced by the older age of this patient population. Our experience supports higher all-cause mortality for TTC compared with the age- and sex-matched general population. Excess mortality occurred predominantly within the first year after the TTC event, usually because of malignancy or noncardiac conditions. ${ }^{7}$ In contrast, in a relatively small study, post-hospital survival at 4 years did not differ significantly from that of an age- and sexmatched general population. ${ }^{77}$

Recurrence TTC events may recur in $5-10 \%$ of patients and appear as early as 3 weeks or as late as 4 years after the initial event. ${ }^{7,77}$ Repeated or serial TTC has been encountered. We have treated a female patient who has experienced 6 separate TTC events between 2003 and 2012, of which 5 were triggered by an emotional stressor. Notably, in patients with recurrent TTC, the LV ballooning pattern may differ; for example, with apical ballooning during the initial event and midventricular ballooning during the second event. ${ }^{78}$ Initial and recurrent TTC events have been reported in patients receiving $\beta$-blocker therapy, typically administered for coexisting systemic hypertension. In our cohort, $18 \%$ of patients were receiving $\beta$-blocker drugs at the time of their initial TTC event, and $43 \%$ at the time of a recurrent episode. ${ }^{7}$ Based on this observational evidence it would appear that $\beta$-blockers are not absolutely protective against TTC.

\section{References}

1. Dote K, Sato H, Tateishi H, Uchida T, Ishihara M. Myocardial stunning due to simultaneous multivessel coronary spasms: A review of 5 cases. J Cardiol 1991; 21: 203-214 (in Japanese).

2. Pavin D, Le Breton H, Daubert C. Human stress cardiomyopathy mimicking acute myocardial syndrome. Heart 1997; 78: 509-511.

3. Sharkey SW, Shear W, Hodges M, Herzog CA. Reversible myocardial contraction abnormalities in patients with an acute noncardiac illness. Chest 1998; 114: 98-105.

4. Tsuchihashi K, Ueshima K, Uchida T, Oh-mura N, Kimura K, Owa $\mathrm{M}$, et al. Transient left ventricular apical ballooning without coronary artery stenosis: A novel heart syndrome mimicking acute myocardial infarction: Angina Pectoris-Myocardial Infarction Investigations in Japan. J Am Coll Cardiol 2001; 38: 11-18.

5. Kurisu S, Sato H, Kawagoe T, Ishihara M, Shimatani Y, Nishioka K, et al. Tako-tsubo-like left ventricular dysfunction with ST-segment elevation: A novel cardiac syndrome mimicking acute myocardial infarction. Am Heart J 2002; 143: 448-455.

6. Sharkey SW, Lesser JR, Zenovich AG, Maron MS, Lindberg J, Longe $\mathrm{TF}$, et al. Acute and reversible cardiomyopathy provoked by stress in women from the United States. Circulation 2005; 111: 472-479.

7. Sharkey SW, Windenburg DC, Lesser JR, Maron MS, Hauser RG, Lesser JN, et al. Natural history and expansive clinical profile of stress (tako-tsubo) cardiomyopathy. J Am Coll Cardiol 2010; 55: 333-341.

8. Abe Y, Kondo M, Matsuoka R, Araki M, Dohyama K, Tanio H. Assessment of clinical features in transient left ventricular apical ballooning. J Am Coll Cardiol 2003; 41: 737-742.

9. Seth PS, Aurigemma GP, Krasnow JM, Tighe DA, Untereker WJ, Meyer TE. A syndrome of transient left ventricular apical wall motion abnormality in the absence of coronary disease: A perspective from the United States. Cardiology 2003; 100: 61-66.

10. Desmet WJ, Adriaenssens BF, Dens JA. Apical ballooning of the left ventricle: First series in white patients. Heart 2003; 89: 1027-1031.

11. Bybee KA, Kara T, Prasad A, Lerman A, Barsness GW, Wright RS, et al. Systematic review: Transient left ventricular apical ballooning: A syndrome that mimics ST-segment elevation myocardial infarction. Ann Intern Med 2004; 141: 858-865.

12. Wittstein IS, Thiemann DR, Lima JA, Baughman KL, Schulman SP, Gerstenblith G, et al. Neurohumoral features of myocardial stunning due to sudden emotional stress. N Engl J Med 2005; 352: 539-548.

13. Maron BJ, Towbin JA, Thiene G, Antzelevitch C, Corrado D, Arnett $\mathrm{D}$, et al; American Heart Association; Council on Clinical Cardiology, Heart Failure and Transplantation Committee; Quality of Care and Outcomes Research and Functional Genomics and Translational Biology Interdisciplinary Working Groups; Council on Epidemiology and Prevention Contemporary definitions and classification of the cardiomyopathies. An American Heart Association Scientific Statement from the Council on Clinical Cardiology, Heart Failure and Transplantation Committee; Quality of Care and Outcomes Research and Functional Genomics and Translational Biology Interdisciplinary Working Groups; and Council on Epidemiology and Prevention. Circulation 2006; 113: 1807-1816.

14. Sharkey SW, Lesser JR, Maron MS, Maron BJ. Why not just call it tako-tsubo cardiomyopathy: A discussion of nomenclature. $J$ Am Coll Cardiol 2011; 57: 1496-1497.

15. Bossone E, Erbel R. The "takotsubo syndrome": From legend to science. Heart Fail Clin 2013; 9: xiii-xv.

16. Ghadri JR1, Ruschitzka F, Lüscher TF, Templin C. Takotsubo cardiomyopathy: Still much more to learn. Heart 2014 April 7, doi: 10.1136/heartjnl-2013-304691.

17. Akashi YJ, Goldstein DS, Barbaro G, Ueyama T. Takotsubo cardiomyopathy: A new form of acute, reversible heart failure. Circulation 2008; 118: 2754-2762.

18. Bybee KA, Prasad A. Stress-related cardiomyopathy syndromes. Circulation 2008; 118: 397-409.

19. Ahmed S, Ungprasert P, Ratanapo S, Hussain T, Riesenfeld EP. Clinical characteristics of takotsubo cardiomyopathy in North America. N Am J Med Sci 2013; 5: 77-81.

20. Schneider B, Athanasiadis A, Sechtem U. Gender-related differences in takotsubo cardiomyopathy. Heart Fail Clin 2013; 9: 137-146, vii.

21. Citro R, Rigo F, D'Andrea A, Ciampi Q, Parodi G, Provenza G, et al. Echocardiographic correlates of acute heart failure, cardiogenic shock, and in-hospital mortality in tako-tsubo cardiomyopathy. JACC Cardiovasc Imaging 2014; 7: 119-129.

22. Aizawa K, Suzuki T. Takotsubo cardiomyopathy: Japanese perspective. Heart Fail Clin 2013; 9: 243-247.

23. Schoof S, Bertram H, Hohmann D, Jack T, Wessel A, Yelbuz TM. Takotsubo cardiomyopathy in a 2-year-old girl: 3-dimensional visualization of reversible left ventricular dysfunction. J Am Coll Cardiol 2010; 55: e5, doi:10.1016/j.jacc.2009.08.050.

24. Brezina $\mathrm{P}$, Isler $\mathrm{CM}$. Takotsubo cardiomyopathy in pregnancy. $\mathrm{Ob}$ stet Gynecol 2008; 112: 450-452.

25. Kurisu S, Kihara Y. Tako-tsubo cardiomyopathy: Clinical presentation and underlying mechanism. J Cardiol 2012; 60: 429-437.

26. Elesber AA, Prasad A, Bybee KA, Valeti U, Moktiei A, Lerman A, et al. Transient cardiac apical ballooning syndrome: Prevalence and clinical implications of right ventricular involvement. J Am Coll Cardiol 2006; 47: 1082-1083.

27. Deshmukh A, Kumar G, Pant S, Rihal C, Murugiah K, Mehta JL. Prevalence of Takotsubo cardiomyopathy in the United States. Am Heart J 2012; 164: 66-71.

28. Nascimento FO, Larrauri-Reyes MC, Santana O, Perez-Caminero M, Lamas GA. Comparison of stress cardiomyopathy in Hispanic and non-Hispanic patients. Rev Esp Cardiol (Engl Edn) 2013; 66: 67-68.

29. Maekawa Y. Direct comparison of Takotsubo cardiomyopathy between Japan and USA: 3-year follow-up study. Intern Med 2012; 51: $257-262$.

30. Sharkey SW, Lesser JR, Garberich RF, Pink VR, Maron MS, Maron BJ. Comparison of circadian rhythm patterns in Tako-tsubo cardiomyopathy versus ST-segment elevation myocardial infarction. Am J Cardiol 2012; 110: 795-799.

31. Manfredini R, Salmi R, Fabbian F, Manfredini F, Gallerani M, Bossone E. Breaking heart: Chronobiologic insights into takotsubo 
cardiomyopathy. Heart Fail Clin 2013; 9: 147-156, vii-viii.

32. Deshmukh A, Pant S, Badheka A, Deshmukh AA, Kumar G. Seasonal variation of takotsubo cardiomyopathy. Am J Cardiol 2013; 111: $627-628$.

33. Manfredini R, Fabbian F, Manfredini F, Eagle KA, Bossone E. Takotsubo cardiomyopathy and summer: A dangerous liaison? Am Heart J 2013; 165: e5, doi:10.1016/j.ahj.2012.10.011.

34. Watanabe H, Kodama M, Okura Y, Aizawa Y, Tanabe N, Chinushi $\mathrm{M}$, et al. Impact of earthquakes on Takotsubo cardiomyopathy. JAMA 2005; 294: 305-307.

35. Butterly SJ, Indrajith M, Garrahy P, Ng AC, Gould PA, Wang WY. Stress-induced takotsubo cardiomyopathy in survivors of the 2011 Queensland floods. Med J Aust 2013; 198: 109-110.

36. Prasad A, Lerman A, Rihal CS. Apical ballooning syndrome (TakoTsubo or stress cardiomyopathy): A mimic of acute myocardial infarction. Am Heart J 2008; 155: 408-417.

37. Park JH, Kang SJ, Song JK, Kim HK, Lim CM, Kang DH, et al. Left ventricular apical ballooning due to severe physical stress in patients admitted to the medical ICU. Chest 2005; 128: 296-302.

38. Haghi D, Fluechter S, Suselbeck T, Saur J, Bheleel O, Borggrefe M, et al. Takotsubo cardiomyopathy (acute left ventricular apical ballooning syndrome) occurring in the intensive care unit. Intensive Care Med 2006; 32: 1069-1074.

39. Summers MR, Prasad A. Takotsubo cardiomyopathy: Definition and clinical profile. Heart Fail Clin 2013; 9: 111-122, vii.

40. Agarwal V, Kant G, Hans N, Messerli FH. Takotsubo-like cardiomyopathy in pheochromocytoma. Int J Cardiol 2011; 153: 241 - 248.

41. Kim S, Yu A, Filippone LA, Kolansky DM, Raina A. Inverted-Takotsubo pattern cardiomyopathy secondary to pheochromocytoma: A clinical case and literature review. Clin Cardiol 2010; 33: 200-205.

42. Abraham J, Mudd JO, Kapur N, Klein K, Champion HC, Wittstein IS. Stress cardiomyopathy after intravenous administration of catecholamines and beta-receptor agonists. J Am Coll Cardiol 2009; 53: $1320-1325$.

43. Kosuge M, Kimura K. Clinical implications of electrocardiograms for patients with anterior wall ST-segment elevation acute myocardial infarction in the interventional era. Circ J 2012; 76: 32-40.

44. Sharkey SW, Lesser JR, Menon M, Parpart M, Maron MS, Maron BJ. Spectrum and significance of electrocardiographic patterns, troponin levels, and thrombolysis in myocardial infarction frame count in patients with stress (tako-tsubo) cardiomyopathy and comparison to those in patients with ST-elevation anterior wall myocardial infarction. Am J Cardiol 2008; 101: 1723-1728.

45. Bybee KA, Motiei A, Syed IS, Kara T, Prasad A, Lennon RJ, et al. Electrocardiography cannot reliably differentiate transient left ventricular apical ballooning syndrome from anterior ST-segment elevation myocardial infarction. J Electrocardiol 2007; 40: 38.e1-e6, doi:10.1016/j.jelectrocard.2006.04.007.

46. Kosuge M, Ebina T, Hibi K, Iwahashi N, Tsukahara K, Endo M, et al. Differences in negative T waves between takotsubo cardiomyopathy and reperfused anterior acute myocardial infarction. Circ $J$ 2012; 76: 462-468.

47. Syed FF, Asirvatham SJ, Francis J. Arrhythmia occurrence with takotsubo cardiomyopathy: A literature review. Europace 2011; 13: 780-788.

48. Fröhlich GM, Schoch B, Schmid F, Keller P, Sudano I, Lüscher TF, et al. Takotsubo cardiomyopathy has a unique cardiac biomarker profile: NT-proBNP/myoglobin and NT-proBNP/troponin T ratios for the differential diagnosis of acute coronary syndromes and stress induced cardiomyopathy. Int J Cardiol 2012; 154: 328-332.

49. Nguyen TH, Neil CJ, Sverdlov AL, Mahadavan G, Chirkov YY, Kucia AM, et al. N-terminal pro-brain natriuretic protein levels in takotsubo cardiomyopathy. Am J Cardiol 2011; 108: 1316-1321.

50. Eitel I, von Knobelsdorff-Brenkenhoff F, Bernhardt P, Carbone I, Muellerleile K, Aldrovandi A, et al. Clinical characteristics and cardiovascular magnetic resonance findings in stress (takotsubo) cardiomyopathy. JAMA 2011; 306: 277-286.

51. Hurst RT, Askew JW, Reuss CS, Lee RW, Sweeney JP, Fortuin FD, et al. Transient midventricular ballooning syndrome: A new variant. $J$ Am Coll Cardiol 2006; 48: 579-583.

52. Sharkey SW. Takotsubo cardiomyopathy: Natural history. Heart Fail Clin 2013; 9: 123 -136, vii.

53. Ibáñez B, Navarro F, Farré J, Marcos-Alberca P, Orejas M, Rábago $\mathrm{R}$, et al. Tako-tsubo syndrome associated with a long course of the left anterior descending coronary artery along the apical diaphragmatic surface of the left ventricle. Rev Esp Cardiol (Engl Edn) 2004; 57: $209-216$

54. Stahl B. Isolated right ventricular ballooning. Eur Heart J 2011; 32: 1821.

55. Mitchell JH, Hadden TB, Wilson JM, Achari A, Muthupillai R,
Flamm SD. Clinical features and usefulness of cardiac magnetic resonance imaging in assessing myocardial viability and prognosis in takotsubo cardiomyopathy (transient left ventricular apical ballooning syndrome). Am J Cardiol 2007; 100: 296-301.

56. Alexanderson E. Transient perfusion and motion abnormalities in takotsubo cardiomyopathy. J Nucl Cardiol 2007; 14: 129-133.

57. Sato A, Aonuma K, Nozato T, Sekiguchi Y, Okazaki O, Kubota K, et al. Stunned myocardium in transient left ventricular apical ballooning: A serial study of dual I-123 BMIPP and Tl-201 SPECT. $J$ Nucl Cardiol 2008; 15: 671-679.

58. Obunai K, Misra D, Van Tosh A, Bergmann SR. Metabolic evidence of myocardial stunning in takotsubo cardiomyopathy: A positron emission tomography study. J Nucl Cardiol 2005; 12: 742-744.

59. Prasad A, Madhavan M, Chareonthaitawee P. Cardiac sympathetic activity in stress-induced (takotsubo) cardiomyopathy. Nat Rev Cardiol 2009; 6: 430-434.

60. Bybee KA, Prasad A, Barsness GW, Lerman A, Jaffe AS, Murphy JG, et al. Clinical characteristics and thrombolysis in myocardial infarction frame counts in women with transient left ventricular apical ballooning syndrome. Am J Cardiol 2004; 94: 343-346.

61. Reynolds HR, Srichai MB, Iqbal SN, Slater JN, Mancini GB, Feit F, et al. Mechanisms of myocardial infarction in women without angiographically obstructive coronary artery disease. Circulation 2011; 124: $1414-1425$.

62. Kurisu S. Prevalence of incidental coronary artery disease in takotsubo cardiomyopathy. Coron Artery Dis 2009; 20: 214-218.

63. Medeiros K, O'Connor MJ, Baicu CF, Fitzgibbons TP, Shaw P, Tighe DA, et al. Systolic and diastolic mechanics in stress cardiomyopathy. Circulation 2014; 129: 1659-1667.

64. Good CW, Hubbard CR, Harrison TA, Qureshi A. Echocardiographic guidance in treatment of cardiogenic shock complicating transient left ventricular apical ballooning syndrome. JACC Cardiovasc Imaging 2009; 2: 372-374.

65. El Mahmoud R, Mansencal N, Pilliére R, Leyer F, Abbou N, Michaud $\mathrm{P}$, et al. Prevalence and characteristics of left ventricular outflow tract obstruction in tako-tsubo syndrome. Am Heart J 2008; 156: $543-548$.

66. Liang JJ, Cha YM, Oh JK, Prasad A. Sudden cardiac death: An increasingly recognized presentation of apical ballooning syndrome (Takotsubo cardiomyopathy). Heart Lung 2013; 42: 270-272.

67. Madias C, Fitzgibbons TP, Alsheikh-Ali AA, Bouchard JL, Kalsmith B, Garlitski AC, et al. Acquired long QT syndrome from stress cardiomyopathy is associated with ventricular arrhythmias and torsades de pointes. Heart Rhythm 2011; 8: 555-561.

68. Samuelov-Kinori L, Kinori M, Kogan Y, Swartzon M, Shalev H, Guy $\mathrm{D}$, et al. Takotsubo cardiomyopathy and QT interval prolongation: Who are the patients at risk for torsades de pointes? J Electrocardiol 2009; 42: 353-357.e1, doi:10.1016/j.jelectrocard.2009.01.005.

69. Fernández-Pérez GC, Aguilar-Arjona JA, de la Fuente GT, Samartín M, Ghioldi A, Arias JC, et al. Takotsubo cardiomyopathy: Assessment with cardiac MRI. Am J Roentgenol 2010; 195: 139-145.

70. Joe BH, Jo U, Kim HS, Park CB, Hwang HJ, Sohn IS, et al. APACHE II score, rather than cardiac function, may predict poor prognosis in patients with stress-induced cardiomyopathy. $J$ Korean Med Sci 2012; 27: 52-57.

71. Brinjikji W, El-Sayed AM, Salka S. In-hospital mortality among patients with takotsubo cardiomyopathy: A study of the National Inpatient Sample 2008 to 2009. Am Heart J 2012; 164: 215-221.

72. Singh K, Carson K, Shah R, Sawhney G, Singh B, Parsaik A, et al. Meta-Analysis of clinical correlates of acute mortality in takotsubo cardiomyopathy. Am J Cardiol 2014; 113: 1420-1428.

73. Akashi YJ, Tejima T, Sakurada H, Matsuda H, Suzuki K, Kawasaki $\mathrm{K}$, et al. Left ventricular rupture associated with Takotsubo cardiomyopathy. Mayo Clin Proc 2004; 79: 821-824.

74. Kumar S, Kaushik S, Nautiyal A, Choudhary SK, Kayastha BL, Mostow N, et al. Cardiac rupture in takotsubo cardiomyopathy: A systematic review. Clin Cardiol 2011; 34: 672-676.

75. Jaguszewski M, Fijalkowski M, Nowak R, Czapiewski P, Ghadri JR, Templin C, et al. Ventricular rupture in Takotsubo cardiomyopathy. Eur Heart J 2012; 33: 1027.

76. Izumi K, Tada S, Yamada T. A case of Takotsubo cardiomyopathy complicated by ventricular septal perforation. Circ J 2008; 72: $1540-1543$

77. Elesber AA, Prasad A, Lennon RJ, Wright RS, Lerman A, Rihal CS. Four-year recurrence rate and prognosis of the apical ballooning syndrome. J Am Coll Cardiol 2007; 50: 448-452.

78. Xu B, Williams PD, Brown M, Macisaac A. Takotsubo cardiomyopathy: Does recurrence tend to occur in a previously unaffected ventricular wall region? Circulation 2014; 129: e339-e340, doi: 10.1161/CIRCULATIONAHA.113.007015. 